\title{
Labour in Global Value Chains: Work Conditions in Football Manufacturing in China, India and Pakistan
}

\author{
Peter Lund-Thomsen, Khalid Nadvi, Anita Chan, Navjote \\ Khara and Hong Xue
}

\begin{abstract}
A critical challenge facing developing country producers is to meet international labour standards and codes of conduct in order to engage in global value chains. Evidence of gains for workers from compliance with such standards and codes remains limited and patchy. This article focuses on the global football industry, a sector dominated by leading global brands that manage dispersed global value chains. It assesses the working conditions for football stitchers engaged in different forms of work organization, factories, stitching centres and home-based settings in Pakistan, India and China. It draws on detailed qualitative primary field research with football-stitching workers and producers in these three countries. The article explains how and why work conditions of football stitchers differ across these locations through an analytical framework that interweaves both global and local production contexts that influence work conditions. In doing so, it argues that current debates on the role of labour in global value chains have to go beyond a narrow focus on labour standards and corporate social responsibility compliance and engage with economic, technological and social upgrading as factors that could generate sustained improvements in real wages and workers' conditions.
\end{abstract}

\section{INTRODUCTION}

Football is considered the most popular sport on the planet. It is a major global industry with its star players, leading international clubs and major tournaments idolized, followed and watched across the farthest corners of the globe. Little attention is paid by fans, however, to how the ball itself, the very heart of the game, is produced. This article focuses on workers engaged in football production in the main centres of global football

The authors thank the United Nations Industrial Development Organization (UNIDO) for funding an initial comparative study on football production in the Sialkot (Pakistan) and Jalandhar (India) clusters, and the Danish Social Sciences Research Council for financing the subsequent study of workers in football manufacturing in China, India and Pakistan. Of course, neither funding body is responsible for the findings and views presented here. The authors acknowledge inputs from participants at various workshops where drafts of this paper were presented and are grateful for the helpful comments provided by the reviewers. The authors are collectively responsible for any errors.

Development and Change 00(0): 1-27. DOI: 10.1111/j.1467-7660.2012.01798.x

(C) 2012 International Institute of Social Studies.

Published by Blackwell Publishing, 9600 Garsington Road, Oxford OX4 2DQ, UK and 350 Main St., Malden, MA 02148, USA 
manufacture - China, Pakistan and, to a lesser extent, India. While iconic international football players can easily command salaries in excess of US\$ 1 million a month, workers engaged in football manufacturing are among the lowest paid and least skilled in their respective countries. Drawing on extensive primary evidence, the article assesses work conditions for those who stitch footballs in China, Pakistan and India, analyses what may account for the differences in these conditions, and seeks to explain the systemic position of workers at the very bottom of the global value chain (GVC) in football production. ${ }^{1}$

In line with the growing popularity of the sport, international trade in inflatable balls has grown systematically over the past decade, peaking at US\$ 1.26 billion in 2010 (UN Comtrade, 2011). ${ }^{2}$ A small number of leading global brands dominate the organization of global football manufacturing. These include Adidas, Asics, Mitre, Mizuno, Nike, Puma, Reebok and Umbro (Lund-Thomsen and Nadvi, 2010). These brands sponsor leading football teams such as Barcelona and Chelsea and sell high-quality 'match' balls used in professional football leagues and tournaments across Europe and North America. For example, in the 2010 World Cup tournament, the official Adidas match ball, produced with the use of mechanized, thermomoulded technology, retailed at approximately US\$ 185 a ball whereas a hand-stitched match ball could be purchased for approximately US\$ 85-135 per ball in outlet stores in Northern Europe. The global brands also market medium-quality hand-stitched or machine-stitched training balls that tend to be used in lower league matches or club practice, often retailing in the range of US\$ 15-35 per ball. In addition, there is a substantial market for promotional hand-stitched or machine-stitched footballs that are used as part of broader marketing campaigns of non-sports brands. For instance, in the run-up to World Cup or European Cup Championships, many global brands offer their customers a free football with their purchase as part of their brand marketing campaigns.

In recent years, there has been greater consolidation among the brands, with Adidas acquiring Reebok in 2005 and Nike taking over Umbro in 2007. By 2009, Adidas - in its own estimate - accounted for 34 per cent of the global football business and reported sales of US\$ 1.57 billion from football-related merchandizing, whereas Nike generated US\$ 1.7 billion from sales of footballs and football-related products (Nadvi et al., 2011). Brands source footballs from independent suppliers in four distinct Asian production locations - China, Pakistan, Thailand and India. China

1. GVCs are here defined as inter-firm networks through which products and services are designed, manufactured, distributed, marketed and recycled across multiple geographical locations in different regions of the world.

2. Inflatable balls include volleyballs, rugby balls and basketballs as well as footballs. Footballs, or what in the United States are referred to as soccer balls, are considered the largest single category and are the focus of this study. 
dominates the manufacture of low- to medium-quality machine-stitched balls, while Pakistan is the leading producer for high-quality hand-stitched match balls. Thailand's niche was premium thermo-moulded balls, but these are now also produced in China. India's production is primarily of low- to medium-quality hand-stitched footballs.

There have been two key developments in football manufacturing in recent years. First, given the global cultural prominence of the sport, and the high profile of the leading brands, a range of labour standard concerns have affected GVCs in football manufacturing. This led to the implementation of multi-stakeholder initiatives to monitor against, and address the causes of, child labour in Pakistan and India (Lund-Thomsen and Nadvi, 2010). In China, pressures on overtime, working conditions and concerns with the potential use of prison labour has led to stricter enforcement of codes of conduct by brands in the Chinese value chains (Nadvi et al., 2011). Second, there has been systematic technological upgrading in product and process activities, with more advanced footballs and more mechanized forms of production. However, technological upgrading has been geographically uneven with China taking the lead and South Asia attempting to catch up (Nadvi, 2011).

This article contributes to the literature on labour in GVCs through empirical evidence. We assess the similarities and the differences in the work conditions of football stitchers engaged in factory, stitching-centre and homebased work in Pakistan, India and China and try to explain why we observe these similarities and differences. We draw on detailed comparative research undertaken in the three countries from 2008 to 2010, including interviews with suppliers, contractors and workers as well as the leading global brands. Finally, we argue that it is important to explore how the sourcing and corporate social responsibility $(\mathrm{CSR})^{3}$ policies of internationally branded companies affect work conditions at supplier factories in developing countries. However, it is just as important to recognize that a broader set of local and global causal factors are likely to influence workers' conditions in exportoriented industries. We suggest this might be achieved by drawing on insights gained from a range of interrelated literatures including work on GVCs, on industrial upgrading in these chains, and on local production organization.

The article is structured as follows. The first two sections briefly describe the core features and trends in the global football manufacturing industry, and give details of our methodology. The paper then presents an analytical framework to explain how similarities and differences in work conditions in the labour-intensive, export-oriented football manufacturing industry can be understood, and charts the main findings on work conditions and outcomes for factory-based, centre-based and home-based football stitchers in Pakistan, India and China. The penultimate section provides an analytical

3. CSR is here defined as firms integrating economic, social and environmental considerations within their core business practices and their interaction with their stakeholders. 
Figure 1. Exports of Inflatable Balls for China, Pakistan, Thailand and India, 2003-2011

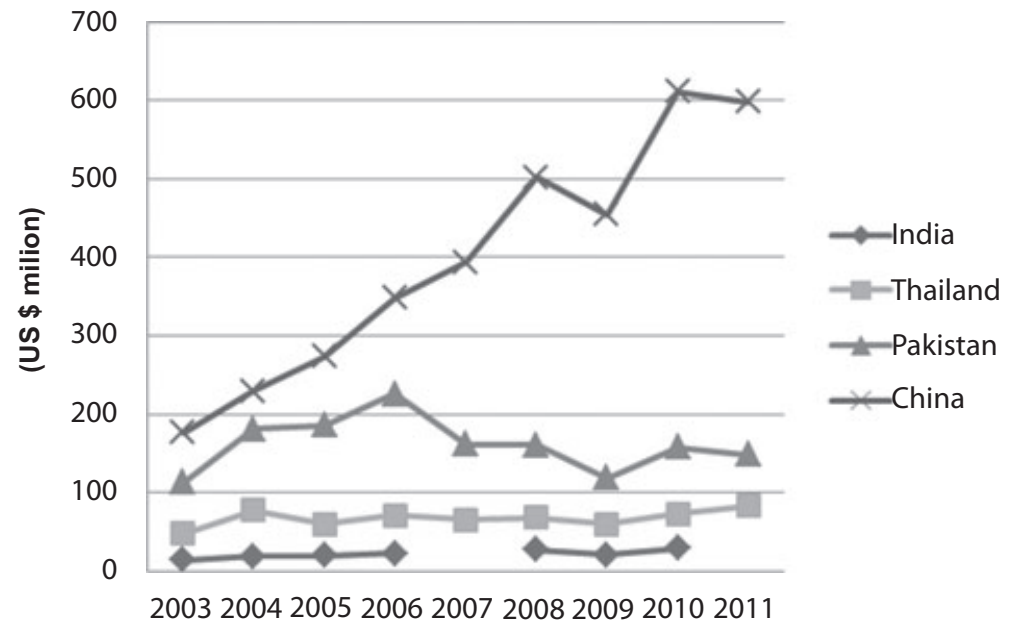

Source: UN Comtrade 2011 data for HS950662 (India data missing for 2007).

explanation behind the differences in wages and work conditions across the three locations and their relationship to industrial upgrading/downgrading, GVC governance, and production organization in national institutional contexts. Finally, the conclusion considers the implications of this study for further policy and research on labour in GVCs.

\section{THE GLOBAL FOOTBALL MANUFACTURING INDUSTRY: A BRIEF OVERVIEW}

As Figure 1 shows, China's dominance in global exports of inflatable balls has been growing since 2003, whereas Thailand and India have been largely stagnant during the same period. Pakistan saw growth in exports between 2003 and 2006. From 2006 to 2009 export volumes declined. In 2010, the year of the World Cup in South Africa, export volumes improved for all four countries, but most dramatically for China. As a consequence, the gap between China and the world's second biggest manufacturer, Pakistan, is widening.

The Pakistani football industry consists of around 390 producers located in and around the city of Sialkot in Punjab. This used to be the world's leading centre for football manufacturing until the late 1990s. Sialkot's producers traditionally prided themselves on their knowledge of high-quality handstitching with the Sialkot cluster producing the entire range of high-quality match balls, medium-quality training balls and lower-quality promotional balls. The Chinese football manufacturing sector consists of approximately 
200 suppliers (Global Sources, 2006). Chinese factories predominantly use machine-stitching technology. Football manufacturing is concentrated in Guangdong and Jiangsu provinces. Some of the largest manufacturers are also located in Fujian and Jiangxi provinces and in Shanghai. Investments from Hong Kong and Taiwan played a key role in the development of the Chinese football industry. The Indian football manufacturing industry is mainly located in the city of Jalandhar. The Jalandhar cluster is relatively small with only 150 exporting enterprises and a daily output of 45,000 inflatable balls. By contrast, the largest machine-stitching factory in China can produce 70,000 footballs a day. Jalandhar specializes in the hand-stitching of footballs although a few manufacturers have now also started machine-stitching. In Thailand, football production is dominated by a few large producers engaged in machine-stitching of footballs. The profile of Thailand's football manufacturing industry was raised in 2004 when the Japanese-owned firm, Molten, produced the first mechanized thermo-moulded ball for Adidas. This was used for the European Cup tournament. However, in 2010 Adidas shifted its sourcing of thermo-moulded balls from Thailand to a supplier in Guangdong, China.

A common feature of the football manufacturing industry in Pakistan, India and, to a lesser extent, China is the extensive use of subcontracting. In Pakistan and India, the process of stitching the balls is outsourced from the factory to keep overhead costs down, circumvent local labour laws and retain flexibility in relation to seasonal changes in football demand. Outsourcing is done through subcontractors of whom there are approximately 2,450 in Sialkot and 1000 in Jalandhar (Lund-Thomsen and Nadvi, 2009). They serve as a link between suppliers and stitchers in both Sialkot and Jalandhar. Only one or two firms in each cluster directly employ their own stitchers. In both clusters, stitchers are generally either employed by the subcontractors or are self-employed, and are paid on a piece-rated basis, with rates varying according to the type and quality of ball being stitched. In Sialkot, stitching takes place in 2,600 registered stitching centres and in Jalandhar approximately 3,000 registered centres have been identified. Stitching centres are designated sites - such as a rented building or an open courtyard - where the stitching of footballs takes place. Centres are usually managed by subcontractors, and each centre is linked to, and undertakes work for, a specific manufacturer. Registration implies that these centres are monitored by the child labour monitoring programmes that operate in each cluster (Lund-Thomsen and Nadvi, 2010).

Stitching centres vary in size. Sialkot's large centres accommodate between 100 and 500 stitchers, medium-sized centres have 50-100 stitchers, smaller centres have 10-50 stitchers, and home-based stitching centres have less than 10 stitchers. In addition, there are some non-registered home-based stitching locations, although it is difficult to estimate their number. Home-based stitching is often a full-time occupation in Sialkot and Jalandhar, although some female stitchers in Sialkot mainly stitch on a 
part-time basis to supplement their family's income. In Jalandhar, approximately thirty stitching centres are small to medium-sized whereas the remainder are home-based units. There are numerous unregistered stitching locations in Jalandhar (Lund-Thomsen and Nadvi, 2009).

In China, the process of subcontracting takes place from larger machinebased first-tier suppliers in Guangdong to smaller second-tier suppliers in Guangdong or other provinces such as Jiangsu where stitching sometimes takes place in townships or rural areas. Subcontracting has been extensively used in relation to the hand-stitching of footballs by some of the larger manufacturers based in Shanghai, which subcontracted to Jiangsu province where stitching was carried out in designated centres, informal workshops or the homes of village-based stitchers. In China, home-based stitching is mostly a part-time activity that helps rural women generate some additional income. Anecdotal evidence obtained through our research suggests that some suppliers, especially smaller producers and subcontractors based in Jiangsu, may be outsourcing some hand- and machine-stitching of footballs to local prisons.

\section{METHODOLOGY}

As an entry point to investigating work conditions among factory, stitchingcentre and home-based stitchers, we undertook a full mapping of the value chains and work forms found in the football manufacturing industries in Pakistan, India and China. This was done through interviews with key informants and academics, as well as with international buyers, local suppliers, contractors/subcontractors and football stitchers in each country. In Pakistan we found home-based, centre-based and factory-based stitching. In India, the dominant work forms were centre- and home-based stitching. ${ }^{4}$ In contrast, factory-based stitching was the only work form observed in the leading football manufacturing region in Guangdong province in South China. In Jiangsu province in East China, the second largest manufacturing region in the country, factory-based and home-based stitching were the dominant work forms although home-based stitching was rapidly disappearing at the time of our fieldwork due to the low wages earned, young people not entering the industry, and the availability of better-paid job alternatives.

Our initial hypothesis was that work conditions in the football manufacturing industries of Pakistan, India and China vary according to the type of work form and value chain that football stitchers are inserted into (see also Lund-Thomsen and Nadvi, 2010). We expected that conditions would

4. Factory-based machine-stitching was introduced in two factories in Jalandhar in 2008/9. However, the total number of these workers - around fifty - could not be considered a dominant work form when compared to the total number of stitchers in the Jalandhar football cluster. 
be better in the more regulated, formal factory work environments where stitchers would be covered by local labour law protection, and worsen as we moved to the semi-formal stitching centres and the informal settings of home-based stitching locations operating outside the remit of labour laws. Similarly, we expected that stitchers were likely to experience the best work conditions if they were engaged in value chains of CSR-sensitive megabrands, such as Nike and Adidas. At the same time, we felt that football stitchers may experience the worst conditions when inserted into chains that supplied non-CSR sensitive buyers.

Based on these considerations we interviewed workers across the range of dominant work forms in each location..$^{5}$ Although our sample sizes of firms and workers are small, and cannot claim to be representative, they were purposively selected to give an indicative picture of dominant work practices in each location. We also interviewed senior sourcing and CSR personnel of leading global and regional brands, including Nike, Adidas, the UK brand Pentland-Mitre, the Danish brand Select Sports and smaller specialized brands such as Fairdeal Trading. Interviews with the brands were carried out in Europe, the United States and with brand's representatives and sourcing offices in Pakistan and China.

In all three countries we interviewed a limited number of chief executive officers and CSR compliance staff from suppliers that fed into the different value chains. In Pakistan we interviewed four large enterprises, three medium-sized enterprises and four small enterprises. ${ }^{6}$ Similarly, we undertook interviews with five medium-sized enterprises and four small enterprises in India. In Guangdong province we undertook six firm interviews, two with large factories, two with small factories and two with trading houses. In Jiangsu province we carried out eleven interviews with small and medium-sized manufacturers. Going further down the value chain we interviewed six subcontractors in Pakistan and seven in India. Our interviews with brands, local suppliers and subcontractors were qualitative in nature and we focused on trying to understand intra-chain relationships, the ways in which concerns about labour standards and CSR factored into these ties, and the implications for the distinct category of actors within the chain.

Finally, we conducted a total of 127 individual open-ended questionnaire interviews with football stitchers in Pakistan, India and China. As shown below (Table 1) these were distributed according to the different work forms prevalent in each location. We used a qualitative purposive sampling methodology ensuring that we interviewed a comparable number of male and female workers belonging to different work forms, supply chains and major

5. Worker interviews were carried out in 2009-10 following earlier rounds of fieldwork with suppliers in each of the three countries.

6. Large enterprises are here defined as firms with 250 or more employees, medium-sized enterprises as having 50-250 employees, and small enterprises as employing fifty workers or less. 
Table 1. Stitching Workers Interviewed by Work Form in Pakistan, India and China

\begin{tabular}{lcccr}
\hline Work Form & Pakistan & India & China & Total \\
\hline Factory-based work & 14 & 0 & 41 & 55 \\
Centre-based work & 19 & 14 & 0 & 33 \\
Home-based work & 17 & 15 & 7 & 39 \\
Total & 50 & 29 & 48 & 127 \\
\hline
\end{tabular}

stitching areas in Pakistan, India and China. No interviews were carried out in work premises as this could compromise workers and impact on the quality of information we obtained. Hence, in Pakistan and India all worker interviews were undertaken in workers' homes, and we used a range of local key informants and snowballing techniques to identify stitchers engaged in different types of work forms. In China, we conducted interviews with workers outside the factories in Guangdong province, usually meeting workers either during their lunch breaks or in the evening when they were not being observed by supervisors and managers. In Jiangsu province, we could only conduct a very limited number of interviews with home-based stitchers due to difficulties in accessing these stitchers. In each location we endeavoured to follow proper ethical protocols, in particular ensuring confidentiality to all respondents.

Our worker-level interviews sought to explore worker backgrounds, working conditions, income levels, skill acquisition, understanding of CSR and labour standard concerns, as well as labour activism and broader worker perceptions of their experience of work. We triangulated the information obtained through these interviews with reviews of international and national newspaper articles in Pakistan, India and China, previous writings on the football industry (e.g. A. Khan, 2007; F.R. Khan, 2007), and through policy documents and reports produced by international aid agencies, local industry organizations and market research companies. We also reviewed the websites - in particular the ethical guidelines - of internationally branded companies and studied national labour laws in each country. We carried out participatory observation during several factory tours, visits to stitching centres, and rural and urban areas where home-based stitching took place. During these visits we took extensive fieldwork notes and produced village and factory profiles of the localities where stitchers lived and worked. In addition, we carried out a wide range of interviews with other stakeholders who had an involvement in the football manufacturing industry. These included interviews with representatives of international agencies in Europe and Asia - most notably the United Nations Industrial Development Organization (UNIDO) and the International Labour Organization (ILO), as well as repeated discussions with local industry associations in Sialkot and Jalandhar, national government officials, non-governmental organizations (NGOs) and trade unions working to support stitchers, as well as ethical and fair trade consultants working in the industry. 


\section{GLOBAL VALUE CHAINS, INDUSTRIAL UPGRADING AND LOCAL PRODUCTION CONTEXTS}

How do we explain the similarities and differences in work conditions of football stitchers in Pakistan, India and China who participate in different work forms and value chains? Two distinct but related bodies of literature have addressed the role of labour in global production. First, scholars working on the inter-related concepts of GVCs and global production networks (GPNs) have argued that global lead firms play a critical role in the organization of GVCs (Gereffi et al., 2005; Kaplinsky, 2005), and that inter-firm relationships within GPNs are both socially embedded and influenced by a range of multi-scalar factors - from government regulations and international trade agreements to local norms and practices (Coe et al., 2008; Henderson et al., 2002). Central to the organization of GVCs and GPNs have been international standards relating to health and safety, quality assurance, environmental impacts and working conditions (Nadvi, 2008; Ponte and Gibbon, 2005). Meeting such standards, it is argued, can be necessary for developing country producers to engage in GVCs (Nadvi and Wältring, 2004). Second, the literature on CSR has sought to understand how firms integrate social and environmental concerns into core business practices in ways that raise value as well as address the interests of distinct stakeholders (Blowfeld and Frynas, 2005; Jenkins et al., 2002). In this area there has been concern with how 'voluntary' CSR codes are implemented by suppliers, the extent to which this permeates down the value chain, and the implications that arise for brands and workers (Barrientos and Smith, 2007; Locke et al., 2009).

The GVC and CSR literatures are beginning to converge as it becomes apparent that the structural dynamics of global competition and global sourcing, which result in higher returns for companies and shareholders and demand lower costs and shorter lead times for workers and suppliers, can accentuate non-compliance with labour standards and codes of conduct. Squaring these two, apparently disarticulated, challenges can be a major struggle for developing country suppliers, leading to calls for more 'just' value chains (Locke et al., 2009). However, a critical gap in both bodies of literature is their limited understanding of the role of labour, in particular the potential gains to, and consequences for, workers arising from their participation in GVCs. In part, this reflects the focus within the GVC and CSR literatures, with firms (or global corporations) viewed as the primary unit of analysis.

Recently, a number of scholars have begun to recognize this disjuncture (Rainnie et al., 2011; Selwyn, 2012). Coe and Jordhus-Lier (2010) have linked the rich literature on labour geography to GPN analysis, and argued for a more critical understanding of labour agency (see also Lund-Thomsen, forthcoming; Riisgaard and Hammer, 2011). Barrientos et al. (2011) and Milberg and Winkler (2011) have explored the inter-relationship between economic and social upgrading within GVCs, and the consequences for 
worker livelihoods and working conditions from engagement with such GVCs. Empirically, there have been attempts to assess the impact of codes of conduct on workers (Barrientos and Smith, 2007; Chan and Siu, 2010; Locke et al., 2007; Sum and Pun, 2005). ${ }^{7}$ Some studies conclude that codes act as 'window dressing' by failing to address core labour rights (Pun, 2005; Xue, 2011). Given this experience, some practitioners and academics have advocated a 'cooperation paradigm' to improve workers' conditions in supplier factories (Locke et al., 2009; Oxfam, 2010). ${ }^{8}$

In seeking to understand outcomes for workers from participation in GVCs we argue that a combination of possible vertical (GVC) and horizontal (national and local institutional context) factors, and their dynamic interaction, is required. The challenge is not to use either vertical analysis or horizontal analysis to understand the conditions of workers in developing countries that produce for global markets. Instead, the challenge is to understand how global and local factors mutually condition, reinforce or contradict one another in different and shifting constellations, thus creating similar and differential outcomes for workers at particular moments in time (Neilson and Pritchard, 2009, 2010). A critical factor, at the level of both vertical (global) and horizontal (local) ties or contexts, is upgrading and its consequences for workers. From this starting point, we develop an analytical framework for understanding the interplay between vertical and horizontal forms of analysis with reference to the international football manufacturing industry. This is inspired by particular bodies of theoretical literature - on industrial upgrading, on GVCs, as well as local forms of production organization in developing countries.

7. Evidence of actual outcomes for workers from such initiatives suggests, however, that gains are at best patchy. Improvements can be identified on tangible issues such as occupational health and safety (OHS) and limits on excessive overtime, but implementation of codes of conduct have had little direct impact on issues of labour rights, such as freedom of association and collective bargaining (Barrientos and Smith, 2007; Chan and Ross, 2003; ETI, 2006). It is also apparent that codes of conduct do not cover more vulnerable segments of the workforce in developing countries, such as home-based, temporary workers or casual workers, many of whom are women (Nelson et al., 2007). Studies have further highlighted the lack of coordination between the purchasing and CSR departments of international brands, and the distinct and competing pressures that they place on global suppliers (Barrientos and Smith, 2007).

8. The main features of this are the need for: (i) better coordination between the purchasing and compliance departments of international brands; (ii) greater cooperation between brands and suppliers to help suppliers upgrade their products and production processes; (iii) greater interaction between brands and local NGOs and trade unions in training workers in their legal rights and the brands' codes of conduct; (iv) adopting a system of 'mature industrial relations' to improve work conditions and secure enabling rights such as freedom of association and the right to collective bargaining; and (v) continued and better engagement by private sector companies, NGOs, trade unions, and/or government representatives within multi-stakeholder initiatives that facilitate cross-sector learning and foster innovative solutions to complex challenges such as child labour or home-based work (Locke et al., 2009; Miller et al., 2010; Usher and Newitt, 2009). 


\section{Industrial Upgrading vs. Downgrading}

We might be able to explain similarities and differences in work conditions at the bottom of GVCs with reference to the literature on industrial upgrading. As more and more low-cost producers enter the global economy, local suppliers in developing countries face a dilemma in terms of how they can survive in the face of increasing competition from other low-cost regions. Hence, developing country suppliers face a choice between engaging in the so-called 'high road' or 'low road' to competitiveness. The aim of the high road is to increase financial returns to local enterprises by engaging in product, process, functional or intersectoral upgrading strategies - that is, producing better products more efficiently, by moving into higher valueadded activities such as design and branding of products, or by employing skills gained in one industry to become competitive in a related industry (Humphrey and Schmitz, 2002; Schmitz, 2004). Suppliers may also adopt a low road to competitiveness that is based upon a downgrading strategy. Downgrading involves moving into lower value-added activities, squeezing labour by providing lower wages, and failing to abide by social and environmental laws that regulate production in export-oriented industries (Gibbon and Ponte, 2005; Kaplinsky, 2005). Thus, we might be able to explain similarities and differences in work conditions within the same export-oriented industry across different producer countries by observing whether local suppliers follow the high or the low road to competitiveness.

\section{Global Value Chain Governance}

In GVCs, lead firms have the potential to exercise considerable influence over their suppliers through their governance of the chain, by deciding what is to be produced, where, under what conditions, and for what price (Gereffi et al., 2005). In the case of football manufacturing, international buyers may play a key role in demanding continuous price reductions from their suppliers or by compelling their suppliers in different regions to compete on the basis of price by informing them of what prices their competitors can offer. Naturally, this severely constrains the financial returns that local suppliers and stitchers can generate from participating in the global football manufacturing value chain. International buyers also play a key role in determining what kinds of footballs are to be produced. By favouring particular types of football, e.g. thermo-moulded or machine-stitched balls over hand-stitched balls, they can influence the amount of work available to local suppliers and stitchers in Pakistan, India and China. Global brands play a key role in coordinating and organizing the GVC for football production by influencing how footballs are to be produced. For example, international buyers often determine how balls are produced by specifying particular technical, social and environmental requirements that local suppliers must abide by. 
This can have either positive or negative implications for workers. On the one hand, the CSR aspirations of global buyers may favour the hiring of full-time, formally registered workers, working in factory-based settings and covered by national labour and environmental legislation. On the other hand, the enforcement of codes of conduct could exclude smaller-scale manufacturers and stitchers employed in the informal economy, e.g. home-based stitchers, from participating in the higher value-added parts of the global football manufacturing chain. Buyers can also influence when footballs are to be produced. International demand for footballs peaks each year between September and March in line with the football season in Europe and the Americas while also following a two-year cycle that coincides with the run up to either the European or World Cup Tournaments. International buyers of footballs mediate this demand by placing their production orders in preparation for these events. The implications for workers of these changing production cycles could either be excessive work - in the form of overtime or too little work, in terms of job and income insecurity.

\section{Local Forms of Production Organization}

Similarly, various forms of local production organization in particular regions may play important roles in determining how and under what conditions footballs are to be stitched. As Neilson and Pritchard $(2009,2010)$ have argued, local forms of production organization are embedded within wider institutional contexts of work and employment. On the one hand, these institutional contexts consist of more formal regulatory regimes and agencies that are entrusted with the promotion of economic and social development priorities. On the other hand, local institutional contexts also embody the informal values and norms held by state officials, private entrepreneurs, NGOs, workers and communities that impact upon production organization and the conditions under which goods and services are produced.

Within this broader institutional context, some localities may, at one extreme, seek to use mass production techniques involving very large firms whose workers have to perform strictly demarcated, often repetitive tasks in producing large volumes of standardized goods. Mass production involves the mechanization of production to achieve economies of scale and forms of work organization that serve to increase productivity, thus lowering unit labour costs (Kiely, 1998). At the other extreme, some localities may seek to be competitive by forming small-firm industrial clusters that are co-located within a defined geographical space. In such clusters, information flows quickly between firms in the cluster; each firm tends to specialize in a given part of the production process; and the use of subcontracting (also known as 'job working') is extensive to meet changing demands of international buyers. In this model of local economic organization, an available pool of skilled workers is found in cluster settings and local support institutions 
develop forward and backward linkages; small firms tend to specialize in small batch production, and to split up individual parts of the value chain into a large number of production units that are closely co-located within the boundaries of the cluster (Kiely, 1998).

Mass production within factories potentially creates the opportunity for workers to engage in collective action through representative trade bodies. Where effective, such forms of labour agency and mobilization can lead to higher wages and better job security. However, being involved in mass production may also result in increased management control and supervision of workers. As a result, workers may adopt a hostile stance towards their employers and use demarcation strategies, only performing what is stated in their employment contract while refusing to share their knowledge of what works and what does not work at the production line with their employers (Bradley et al., 2000). In industrial cluster settings, the use of subcontracting and flexible production might also have advantages for those workers who do not feel that full-time employment serves their particular needs. For some, it may provide better possibilities for combining work and family life.

However, the use of subcontracting in clusters may also have a downside for workers. The kind of reorganization of value chains is often seen as weakening the demands of labour for better work conditions. First, outsourcing is often accompanied by deregulation and decentralized bargaining, as suppliers are unlikely to be covered by collective industry agreements. Second, as witnessed through outsourcing of production to locations in the developing world, the core workforce in the developed world is often under pressure to make concessions on their employment conditions in order to be able to keep their jobs. Third, outsourcing leaves peripheral workers to cope with the disadvantages and risks of cost-cutting and flexibility (Flecket, 2009: $253)$, resulting in income and employment insecurity.

\section{SIMILARITIES AND DIFFERENCES IN WORK CONDITIONS}

Having outlined an analytical framework to help explain similarities and differences in the work conditions of football stitchers, which focused on the role of industrial upgrading/downgrading, GVC governance, and production organization in national institutional contexts, we now present the main findings gleaned from our worker-level interviews of work conditions of factory, centre-based and home-based football stitchers in Pakistan, India and China. An overview of the similarities and differences in work conditions are listed in Table 2. This evidence needs to be treated with some caution given that our sample size in each location and distinct work form was small. Thus, we make no claim that these data are representative. Nevertheless, the data provide indicative insights into differences across the three country locations and work forms. Wages are presented in two ways: first, in purchasing power parity adjusted figures (for monthly wages) in order to obtain a sense of the 
Table 2. An Overview of Work Conditions for Stitchers in Pakistan, India and China by Work Form

\begin{tabular}{|c|c|c|c|c|c|c|}
\hline \multirow[b]{2}{*}{ Work Form } & \multicolumn{3}{|c|}{ Sialkot } & \multicolumn{2}{|c|}{ Jalandhar } & \multirow{2}{*}{$\frac{\text { Guangdong }}{\text { Factory }}$} \\
\hline & Factory & Centre & Home & Centre & Home & \\
\hline $\begin{array}{l}\text { Median monthly wage } \\
\text { (in PPP \$) }\end{array}$ & 262 & 190 & 78 & 182 & 177 & 439 \\
\hline $\begin{array}{l}\text { Median hourly wage } \\
\text { (in nominal US\$) }\end{array}$ & 0.38 & 0.32 & 0.28 & 0.24 & 0.15 & 0.89 \\
\hline Weekly work days & 6.0 & 6.0 & 6.2 & 6.0 & 6.4 & 6.0 \\
\hline Daily work hours $\mathbf{c}$ & 9.1 & 7.8 & 7.5 & 7.2 & 8.1 & 10.3 \\
\hline Child labour & Absent & Absent & Unknown & Limited & Limited & Absent \\
\hline $\begin{array}{l}\text { Unionization and } \\
\text { collective bargaining }\end{array}$ & No & No & No & No & No & No \\
\hline Social insurance & Wide coverage & No & No & No & No & Limited coverage \\
\hline
\end{tabular}

Notes:

a) Wages were calculated in the following ways. For China, the monthly wages were entered as per the responses of the stitchers interviewed. For Pakistan and India, wages were calculated by multiplying the average rate received per football by the stitcher interviewed and then multiplying this by the average number of balls stitched by the stitcher per day. Finally, this number was multiplied by the number of working days for each stitcher month. This method was adopted for India and Pakistan given the low literacy rates amongst football stitchers who were often not in a position to calculate their exact monthly wages. This was then converted into purchasing power parity \$ using the World Bank's PPP conversion rates.

b) In national currencies, the median monthly incomes were as follows in nominal terms: Pakistan - factory PKR 7540; centre PKR 5460; home PKR 2275. In India, centre INR 3000; home INR 2925. In China (Guangdong): factory RMB 1625.

c) For factory-based football stitchers work hours were entered on the basis of actual hours spent inside the factory/the stitching centre for work purposes. For home-based stitchers, we asked about their daily routines, when they began, took breaks, resumed football stitching, and finished at the end of the day. This was necessary as stitchers themselves did not always have a clear idea of how many hours they actually spent on football stitching.

Source: Authors' survey.

relative purchasing power of football stitchers in Pakistan, India and China; and second, using the going market exchange rate adjusted wage figures (for nominal hourly wages) in order to assess the relative competitiveness of wages in the production of goods across the three locations.

What is apparent from our data is that, as expected, factory-based football stitchers earn the highest monthly incomes. This is true across the three country locations as well as within Pakistan (the only location where all three forms of work organization were observed). We present wage data first in terms of purchasing power parity dollars. At the top are Chinese factory-based football stitchers in Guangdong who earned the equivalent of PPP\$ 439 a month. ${ }^{9}$ This was 40 per cent more than their Pakistani factorybased counterparts who earned PPP\$ 262 per month. In terms of centre- and home-based stitchers, we find that Pakistani centre-based football stitchers

9. In contrast, anecdotal evidence suggests that home-based football stitchers in Jiangsu province earn about PPP\$ 65-92 a month. 
and Indian centre- and home-based football stitchers in our sample earn almost identical monthly incomes at PPP\$ 190, 182 and 177 respectively.

When we review the nominal wages (that is to say, converted according to market exchange rates) we see that the wage differences between China and the South Asian locations are even more sharply defined. The hourly nominal wages in Chinese factories (US\$ 0.89) are more than double the hourly wage in Pakistani factories (US\$ 0.38) and more than three times as high as nominal wages in Indian stitching centres (US\$ 0.24). While the PPP wage levels provide an indication of real wages, the nominal hourly wages provide a better sense of how comparative wage rates may affect the sourcing decisions of global buyers.

Football stitching can be seasonal in line with international demand for footballs, and some stitchers especially in India and Pakistan reported that they often did not obtain stitching work for months at a time. However, when there were enough orders, stitchers in Pakistan, India and China generally worked six days a week. ${ }^{10}$ In terms of daily work hours there was an important difference between Chinese and South Asian football stitchers. Chinese factory-based football stitchers in our sample worked longer hours on average (10.3 hours a day) than their South Asian counterparts. Overtime payments did not apply to Pakistani and Indian home- and centre-based stitchers given that they did not have any contract defining their work relationship and working hours with the suppliers whose balls they stitched. In the case of China, however, factory-based stitchers generally indicated that they do work overtime, sometimes receiving payment for this, while home-based stitchers in Jiangsu did not receive any overtime payment. ${ }^{11}$

On occupational health and safety (OHS) our findings reveal that the majority of football stitchers in China using machine-stitching report that they suffer from OHS problems related to football stitching. This is similar to Indian and Pakistani football stitchers using hand stitching, where OHS problems related to deformed fingertips, shoulder and elbow inflammations, arm and back pain were common. In India, 100 per cent of the home-based and centre-based stitchers reported suffering from health-related problems as a result of their stitching work. In Pakistan, some factory-based stitchers indicated that they suffered OHS problem while most centre-based stitchers ( 70.6 per cent) and home-based stitchers ( 93.3 per cent) stated that they had faced OHS problems.

Contrary to earlier research in Sialkot and Jalandhar ${ }^{12}$ we found little evidence to suggest that football stitching was still undertaken with the help of child labour in either Pakistan (Sialkot), India (Jalandhar) or China

10. The average for India is somewhat higher, but not significant given the small number of home-based stitchers in our Indian sample where a few outliers responded that they also worked on Sundays.

11. The number of valid responses in our sample of Pakistani factory-based stitchers was too low to make any firm conclusions regarding overtime in that particular setting.

12. See, for example, Goyal $(2004,2005)$; Husselbee (2000). 
(Guangdong). ${ }^{13}$ Our own field-level observations in Sialkot and Jalandhar suggest that child labour has been substantially diminished if not virtually eliminated from the export-oriented manufacturing of footballs. ${ }^{14}$ In Jiangsu province, we found anecdotal evidence to suggest that prison labour was involved in the stitching of footballs. While we were unable to ascertain how widespread this practice is, a subcontractor in Jiangsu province claimed that he could get us 3,000 balls stitched in a prison while a factory told us that they had set up a production facility for machine-stitching inside a prison. During an internet search we also came across a prison that - in Chinese publicly advertised its ability to supply footballs.

Our research shows that unionization is generally absent in football stitching in Pakistan, India and China. In the one case of factory-based work in Pakistan some attempt has been made to set up workers' committees. However, these have been largely unsuccessful in terms of protecting workers' rights. In India, an official trade union does exist for football stitchers. However, it is largely ineffective, with a limited membership, and receives money from local entrepreneurs to curb its demands. In terms of industrial action, however, we found evidence of factory-based stitchers in Pakistan and China spontaneously organizing to defend their rights. In Pakistan, a strike was spontaneously undertaken with the aim of pressurizing factory management in the main Nike supplier in Sialkot. The strike happened during the financial crisis in mid-2009 when the factory was forced to temporarily lay off a large number of workers. It appeared as if factory management intentionally miscalculated the factory-based stitchers' monthly wages. Once stitchers became aware of this, they stopped work and only resumed once they had obtained a promise from the factory owner that due wages would be paid in full. Similarly, on 7 May 2009, 2,000 workers went on strike in a large export-oriented factory in Guangdong because of the relocation of the factory and the dismissal of workers without full compensation for wages due. ${ }^{15}$ On 7 June 2010 , more than 1,000 workers went on strike at the new factory site and destroyed part of its administrative office because the security guards of the factory had beaten workers. ${ }^{16}$

13. In our field research in India we did come across one stitching family in Batala in which a female stitcher was assisted by her children in some light tasks once they came back from school, while a stitcher working in a centre claimed that children were involved in stitching there but ran away when the child labour monitors come. In Pakistan, the Independent Monitoring Association for Child Labour reported to us that it usually finds two to three children a month during its visits to stitching centres in Sialkot, out of a total work force of approximately 30,000 registered stitchers.

14. A recent NGO report (ILRF/BBVA, 2008) documented the extensive use of child labour in the football manufacturing cluster of Meerut in the Indian state of Uttar Pradesh. However, the football cluster in Meerut is not primarily engaged in export-oriented production whereas this article focuses on the main export-oriented cluster of India, Jalandhar.

15. See http://epaper.nddaily.com/I/html/2009-05/07/content_783623.htm (accessed 2 April 2010).

16. See http://blog.sina.com.cn/s/blog_4999f0bf0100it2k.html (accessed 15 June 2012). 
In terms of social insurance, we found that Pakistani and Chinese factorybased football stitchers mostly had some form of social insurance. In Pakistan, this included health, pension and unemployment benefits whereas in China it related to pension benefits only. However, centre- and homebased stitchers in Pakistan and India were generally not covered by any social insurance. Anecdotal evidence suggests that a similar situation prevails amongst home-based stitchers in Jiangsu province. In Pakistan, however, we found two exceptions where centre-based stitchers were provided with some medical insurance. One was stitchers producing fair trade footballs; the other was stitchers working for one local factory that provided their stitchers with medical insurance and basic education for their children.

\section{FACTORS AFFECTING DIFFERENCES IN WORK CONDITIONS FOR FOOTBALL STITCHERS}

In the previous section we outlined what appeared to be the most significant similarities and differences in the working conditions of Pakistani, Indian and Chinese football stitchers. We now turn to the question of what explains these similarities and differences. Our analysis is structured on the basis of our analytical framework on industrial upgrading/downgrading, GVC governance, and production organization in national institutional contexts. As suggested earlier, global and local factors may mutually condition, reinforce or contradict one another in ways that create distinct outcomes for workers. Here, we set out how some of these factors might affect work conditions.

\section{Industrial Upgrading}

Perhaps the most significant difference in the work conditions of Pakistani, Indian and Chinese football stitchers is that Chinese factory-based workers earn significantly higher wages than football stitchers in India and Pakistan. Part of the explanation as to why the Chinese manufacturers are able to pay their workers higher wages relates to the process upgrading undertaken by Chinese manufacturers. Chinese football manufacturing became prominent on the global stage with the invention of machine-stitching technology and the emergence of mechanized football manufacturing plants in China. This resulted in a dramatic increase in productivity in comparison with handstitched football production in Pakistan and India. Our firm-level qualitative data suggests that a Chinese factory-based machine stitcher can stitch on average 39.8 balls a day whereas the average Pakistani hand stitcher could stitch 4.5 balls a day and the Indian hand stitcher 3.9 balls. This implies that the daily productivity of Chinese factory-based stitchers was 8.6 times higher than their Pakistani counterparts and 10 times higher than their Indian counterparts. If we adjust for the number of hours worked per day, we find 
a similar story. The hourly productivity of machine-based Chinese stitchers in a large export-oriented factory working in teams was approximately 6.9 times higher than Pakistani hand stitchers and 7.8 times higher than that of Indian hand stitchers.

Sialkot's manufacturers have traditionally specialized in the nicheproduction of high-quality hand-stitched balls. They have, however, lost a significant portion of the world market in training and promotional balls in recent years to Chinese competitors. While Pakistani manufacturers continue to emphasize that hand stitching produces higher quality footballs, Chinese manufacturers have realized that the quality of footballs is perhaps not the most crucial factor in the purchasing decisions of end consumers in the mass market for training, recreational and promotional balls. As globally branded firms play a key role in the marketing of these footballs, consumers base their purchasing decisions primarily on the basis of the brand name (Nike, Adidas, etc.) and the price, rather than whether a ball is hand- or machine-stitched in these market segments.

As Pakistani and Indian manufacturers had not yet introduced machinestitching technology they were unable to match the productivity levels of Chinese football manufacturers and were thus forced to squeeze wages of their football stitchers. As our research in both Sialkot and Jalandhar indicated, football stitchers experienced only minor nominal wage increases in the last five to ten years. Consequently, taking account of inflationary pressures, real wages had declined.

Process upgrading - in the form of the invention of machine stitching in China - did not appear to have reduced the OHS risks that Chinese football stitchers face in comparison with their South Asian counterparts. In Pakistan, India and China the majority of hand and machine stitchers that we interviewed complained of injuries to their hands and lower parts of their arms caused by pricking of the needle, as well as back pain arising from sitting for long hours crouched in the same position on the floor, on low stools, or even on production lines.

\section{Global Value Chain Governance}

It also appears that CSR and sourcing strategies adopted in the interaction between international buyers and local suppliers may affect work conditions for football stitchers in each country. This can have both positive and negative effects, creating winners and losers among stitchers participating in different work forms in the industry. The decline of child labour in football stitching in Sialkot and Jalandhar over the last fifteen years can largely be related to a variety of CSR initiatives within the Pakistani and Indian football manufacturing industries. First, child labour monitoring has been introduced in both clusters since the end of the 1990s. While the effectiveness of these monitoring mechanisms has been the subject of both policy and academic 
discussion (see, e.g., Lund-Thomsen and Nadvi, 2010), their establishment has brought about a general impression that the involvement of children in football stitching is illegal. In Pakistan, in particular, the involvement of children in centre-based football stitching would have direct livelihood implications as centres are likely to be closed if child stitchers are found within them. Second, various NGO awareness-raising campaigns in Sialkot and Jalandhar have changed the perception of child labour within local stitching communities. Most stitching parents felt that involving children in football stitching was not helpful to their child's future. On the one hand, it would compromise their schooling. On the other hand, involving them in football stitching from an early age would mean that they could be restricted to an occupation that provided little prospect for socio-economic advancement.

The factory-based model of football stitching facilitates compliance with the international CSR requirements of Western buyers. Generally, these brands prefer that production is in-sourced in factory-based settings where wages, work hours, overtime payments etc. can be more easily controlled than in the informal urban and rural settings of Sialkot and Jalandhar. The factory-based model of production facilitates the access of workers to benefits such as social insurance (health, pension, unemployment etc.) and overtime payments. This was much more widespread under the factorybased model of football stitching in Guangdong than in the centre-based and home-based settings in Sialkot and Jalandhar. Similarly, we observed that the factory-based model of football stitching in Sialkot and Guangdong allowed workers to collectively organize spontaneous strikes in relation to the delayed or incorrect payment of monthly wages (in Pakistan) as well as factory closures and relocations (in China).

Yet the introduction of the factory-based model of football stitching in Pakistan has also had some negative, and unintended, consequences. Nike is the only international brand that insists that football stitching must take place inside the factory premises of its supplier in Sialkot. While this may help workers obtain the minimum wage, social security and overtime payment prescribed under Pakistani law, it does not take into account the socioeconomic reality faced by many of the female stitchers living in the villages surrounding Sialkot who are unable to commute to and from Nike's supplier factory due to patriarchal norms imposed by their male family members. Consequently, there were no female stitchers employed by the Nike supplier at the time of our field research.

Our findings from China illustrate similar kinds of trade-offs in relation to the implementation of CSR requirements of international brands and their effects on workers' conditions. In some factories supplying either the leading brands (Nike or Adidas) or non-sports brands (such as Disney) we found that the implementation of CSR requirements placed limits on the number of hours that stitchers could work a day. In these cases, the maximum number of work hours was ten hours a day, six days a week, with Sundays off. In the non-CSR compliant factories, football stitchers often worked twelve 
hours a day. As all factories, not only in China but also in Pakistan and India, operated on the basis of the piece-rate payment system, the monthly wages of stitchers working in the CSR non-compliant factory were somewhat higher than those of their counterparts working in the Guangdong factories where CSR requirements are more strictly enforced. However, the hourly wage rates of football stitchers in the non-compliant factory tended to be lower than in the 'CSR compliant' factories that supply the mega, smalland medium-sized, and non-sports brands.

Producers in Sialkot, Jalandhar and Guangdong province also face different sourcing pressures through the global value chain. On the one hand, international demand for footballs fluctuates. It peaks in the run-up to the European Cup and the World Cup and then drops immediately after these tournaments end. International demand also changes in relation to the larger cycles of international capitalism, such as the global financial crisis that hit the international football industry in early 2009 . As all three production locations produce footballs in the promotional segment, they also faced downwards pressures on price as international buyers can source these products from all three countries. Hence, price competition in this segment of the market is intense. In sum, local manufacturers have to be able to adjust their production levels to changing international demand, they tend to face constant downwards pressure on prices, they need to develop new footballs and football manufacturing methods, and they have to comply with international CSR standards if they want to sell into the high-end of the international football market.

\section{Local Forms of Production Organization}

In our view, local production organization within Sialkot, Jalandhar and Guangdong plays an important role in the ability of local manufacturers to cope with the pressures that emanate from the GVCs into which they are inserted. At one level, the differences in production organization may reflect macro-level differences in the industrialization models pursued in China, India and Pakistan. China's export-oriented model has been heavily dependent upon foreign direct investment from Taiwan and Hong Kong. Producers in Sialkot and Jalandhar have built their international competitiveness on the basis of cluster-based agglomeration economies. In contrast, manufacturers in Guangdong province have built their export capability on a mass-production model. These different forms of industrial organization have implications for the work conditions of football stitchers in all three settings.

Small-firm industrial clusters may be able to compete in the international economy by specializing in small batch production for niche markets, and by splitting up production processes between large numbers of smaller units that are located within a narrowly defined geographical area. In this form 
of industrial organization, subcontracting and the use of job working are extensive in order to meet the changing demands of international buyers.

This form of industrial organization was well-suited for the kinds of demands that local manufacturers in Sialkot and Jalandhar faced from the early 1970s until the mid-1990s. In the early 1970s, as international demand for footballs began to surge in both Sialkot and Jalandhar, it soon became obvious to local entrepreneurs that it was no longer viable to keep the most labour-intensive part of production inside the factories. As labour laws were strengthened in the early 1970s, and industrial strikes became more frequent (in Sialkot), local entrepreneurs felt that it was too expensive to retain permanent employees at times when football demand was low. This led to the subcontracting of stitching from local factories to the homes of the football stitchers. This added flexibility enabled producers to respond to changing demands as well as allowing them to avoid social protection provisions within the labour laws. At the same time, placing a network of contractors in between the football factories and the stitchers themselves limited the risks of industrial disputes that could disrupt production and/or lead to increased demands for better work conditions in the industry. In our interviews with home- and centre-based football stitchers in Sialkot and Jalandhar we asked whether they ever engaged in any kind of bargaining over stitching rates. Often the answer was that while football stitchers did complain about the rates to their contractors, the contractor would reply that rates were fixed by the factory and could not be changed. The institutionalization of subcontracting made it very difficult for trade unions to form and collective bargaining to emerge. In terms of producing outcomes for workers, outsourcing can result in the risks associated with global capitalism being pushed down to the lowest point of the football stitching chain. The outsourcing of hand-stitching to centre and home-based locations tends to reduce the incomes of football stitchers, resulting in income and occupational insecurity.

We believe that part of the explanation for the longer hours put in by Guangdong's football stitchers relates to their being migrant workers, whereas their counterparts in Sialkot and Jalandhar tend to be local residents. Most of the workers labouring in the Chinese factories have left their home provinces, and their families, to come to Guangdong in order to save as much as possible in the shortest possible time span. With wages paid on a piece-rated basis they can earn more by working longer hours. Hence, notwithstanding the limits on working hours in place in some factories, with overtime Chinese stitchers work more hours per day than their Pakistani and Indian counterparts. There are no migrant workers in Sialkot and just a few in Jalandhar (from the Indian state of Bihar). Since Sialkot's and Jalandhar's football stitchers reside in the same locality, with their families, it may be more difficult for them to work more than seven to eight hours a day if they also have to spend time engaged in domestic and other forms of labour. This is especially true for rural-based stitchers who may have farm and off-farm activities to undertake alongside their football stitching work. In Sialkot and 
Jalandhar, both male and female centre- and home-based stitchers explained that they would not want to work in factory settings as they preferred the flexibility that centre- and/or home-based work allowed them. This enabled them to come and go anytime and to attend to domestic issues during regular work hours.

\section{CONCLUSION}

This article has sought to provide empirical insights into labour in GVCs using the case of the global football manufacturing industry. This industry is dominated by leading global brands that place labour standards and CSR compliance as central tenets of their sourcing strategies. The industry is also heavily concentrated with manufacturing centred on China, Pakistan and to a lesser extent India. Moreover, there is a clear indication from the trade data of the growing competitiveness of China as the leading global location for football manufacturing at the expense in particular of Pakistan, the world's number two supplier. These dynamic trends reflect differences in work practices, productivity and manufacturing technologies, and they have consequences for 'winners' and 'losers' at the level of national suppliers as well as local workers.

We undertook a comparative investigation of work conditions among football stitchers in Pakistan, India and China and attempted to explain why these work conditions are similar or different across the three countries. We argued that the similarities and differences in work conditions of football stitchers can be explained with reference to the intertwined factors of industrial upgrading/downgrading, GVC governance, and different types of local production organization. Our analysis thus confirms the findings of earlier studies in other 'stitching industries', such as garments and footwear, that showed how sourcing and CSR pressures in GVCs have created new forms of work organization and different outcomes for workers across spatial contexts. However, whereas the global garment and footwear industries are highly dispersed in geographical terms, the global football manufacturing industry is concentrated in just a few production locations, enabling a more 'complete' comparative analysis of how these pressures play out across different geographical settings.

In the football manufacturing industry, it appears that Chinese stitchers (in Guangdong) are better off than their South Asian counterparts in Sialkot and Jalandhar. Factory-based football stitchers in Guangdong earn significantly higher monthly wages than football stitchers in Sialkot and Jalandhar. They can save part of their earnings, which only some stitchers in Pakistan can do, while virtually no football stitchers in Jalandhar are able to put any money aside from their stitching work. While freedom of association and collective bargaining are largely absent in all three production locations, Chinese factory-based stitchers in Guangdong appear better able to organize 
protests and strikes that put pressure on their employers than the vast majority of football stitchers in Sialkot and Jalandhar who work across a large geographical area, mostly without any direct relationship between themselves and the factory whose footballs they stitch. In terms of compliance with international CSR demands, it also appears that Chinese factory-based football stitchers tend to have more frequent access to medical insurance, unemployment insurance and overtime payment than their counterparts in Sialkot and Jalandhar. The only exception in South Asia is a supplier to Nike that has in-sourced the process of football stitching in response to pressures from Nike. Hence, it is only in this factory that football stitchers enjoy similar levels of social protection as their counterparts in China. The only way in which the work conditions of Chinese football stitchers in Guangdong may be considered worse than those in Sialkot and Jalandhar is in relation to work hours: football stitchers in Guangdong put in longer hours than their South Asian counterparts.

However, if we take a broader view of work conditions through the perspective of football stitchers themselves, we arrive at a more mixed assessment. First, during the period of our study it appeared as if factory closures in the Chinese football manufacturing industry, in line with the financial downturn of 2009/2010, were more frequent than in Jalandhar or Sialkot, leaving several thousand workers unemployed. Having said that, football production, as gauged through exports from China, grew rapidly over this period. Second, as mentioned, football stitchers in Guangdong generally have to put in longer hours and experience greater work intensity than their counterparts in Sialkot and Jalandhar; this may result in long-term health effects that we have not been able to document as part of this study. Third, Chinese football stitchers working as migrant labourers in Guangdong province are generally denied the benefits of a family life throughout the year. While this may be reflected in higher financial earnings for themselves and their families in the short-term, it is difficult to assess what the long-term emotional and psychological implications of physical separation are for married stitchers, their spouses and children.

This highlights a final challenge posed by this study. While it may be that Chinese football stitchers in Guangdong province are better off in terms of their monthly earnings, any assessment of 'better off' or 'worse off' depends upon the yardstick being used. Working as a football stitcher - whether in Pakistan, India and China - means receiving relatively low wages. Improvements in work outcomes for labour within the industry require an increase not only in productivity but also in wage rates. Improving wages requires the possibility for collective bargaining pressures by workers, which remains relatively limited, especially in India and Pakistan.

This study suggests that codes of conduct focusing on specific aspects of labour standards do not in themselves generate improved livelihoods and working conditions for football stitchers. Moreover, while compliance pressures from the leading global brands may have some positive gains, these 
may well be outweighed by the competitive pressures and risks that brands force onto their suppliers, and the suppliers then push down to the workers. Some categories of workers may become especially vulnerable. To bring about real improvements in working conditions the policy debate has to go beyond labour standards and CSR compliance and engage with the economic, technological and social upgrading that could potentially generate sustained improvements in real wages and working conditions for workers. However, as our article has also illustrated, economic upgrading does not automatically translate into positive outcomes for all types of workers across different value chains and geographical contexts. Hence, an important policy challenge lies in identifying the types of industrial upgrading (or downgrading) that are likely to create winners and losers amongst different categories of workers within different types of industries, value chains and geographical contexts. While industrial upgrading may be an imperative for local firms to survive in the global economy, social safety networks and retraining opportunities need to be put in place for those workers that are displaced by the ever-shifting processes of GVC restructuring.

\section{REFERENCES}

Barrientos, S. and S. Smith (2007) 'Do Workers Benefit from Ethical Trade? Assessing Codes of Labour Practice in Global Production Systems', Third World Quarterly 28(4): 713-29.

Barrientos, S., G. Gereffi and A. Rossi (2011) 'Economic and Social Upgrading in Global Production Networks: A New Paradigm for a Changing World', International Labour Review 150(3-4): 319-40.

Blowfield, M. and J.F. Frynas (2005) 'Setting New Agendas: Critical Perspectives on Corporate Social Responsibility in the Developing World', International Affairs 81(3): 499-513.

Bradley, H., M. Erickson, C. Stephenson and S. Williams (2000) Myths at Work. Cambridge: Polity Press.

Chan, A. and R.J.S. Ross (2003) 'Racing to the Bottom: Industrial Trade without a Social Clause', Third World Quarterly 24(6): 1011-28.

Chan, A. and K. Siu (2010) 'Analysing Exploitation: The Mechanisms Underpinning Low Wages and Excessive Overtime in Chinese Factories', Critical Asian Studies 42(2): 167-90.

Coe, N.M. and D.C. Jordhus-Lier (2010) 'Constrained Agency? Re-evaluating the Geographies of Labour', Progress in Human Geography 35(2): 211-33.

Coe, N.M., P. Dicken and M. Hess (2008) 'Global Production Networks: Realizing the Potential', Journal of Economic Geography 8(3): 271-95.

Ethical Trading Initiative (2006) 'The ETI Code of Labour Practice: Do Workers Really Benefit?'. Brighton: Institute of Development Studies, University of Sussex.

Flecket, J. (2009) 'Outsourcing, Spatial Relocation and the Fragmentation of Employment', Competition and Change 13(3): 251-66.

Gereffi, G., J. Humphrey and T. Sturgeon (2005) 'The Governance of Global Value Chains', Review of International Political Economy 12(1): 78-104.

Gibbon, P. and S. Ponte (2005) Trading Down: Africa, Value Chains and the Global Economy, Philadelphia, PA: Temple University Press.

Global Sources (2006) 'China Sourcing Report: Sports Balls. Essential Sourcing Intelligence for Buyers'. Hong Kong: Trade Media Limited.

Goyal, P. (2004) 'Child Labour in the Sports Goods Industry: Findings from a Survey in Selected Bastis of Jalandhar', Social Change 34(1): 66-74. 
Goyal, P. (2005) Little Hands That Work: Child Labour in Punjab. Ludhiana: PBG Publications. Henderson, J., P. Dicken, M. Hess, N. Coe and H.W.C. Yeung (2002) 'Global Production Networks and the Analysis of Economic Development', Review of International Political Economy 9(3): 436-64.

Humphrey, J. and H. Schmitz (2002) 'How Does Insertion in Global Value Chains Affect Upgrading in Industrial Clusters', Regional Studies 36(9): 1017-27.

Husselbee, D. (2000) 'NGOs as Development Partners to the Corporates: Child Football Stitchers in Pakistan', Development in Practice 10(3-4): 377-89.

International Labor Rights Forum/Bachpan Bochao Andolan (ILRF/BBVA) (2008) 'Child Labor in Football Stitching Activity in India: A Case Study of Meerut District Uttar Pradesh'. Washington, DC and New Delhi: ILRF/BBVA.

Jenkins, R., R. Pearson and G. Seyfang (2002) 'Introduction', in R. Jenkins, R. Pearson and G. Seyfang (eds) Corporate Responsibility and Labour Rights: Codes of Conduct in the Global Economy, pp. 1-12. London: Earthscan.

Kaplinsky, R. (2005) Globalisation, Poverty and Inequality: Between a Rock and a Hard Place. Cambridge: Polity Press.

Khan, A. (2007) Power, Policy and the Discourse on Child Labour in the Football Manufacturing Industry of Sialkot. Karachi: Oxford University Press.

Khan, F.R. (2007) 'Representational Approaches Matter', Journal of Business Ethics 73(1): $77-89$.

Kiely, R. (1998) 'Globalization, Post-Fordism and the Contemporary Context of Development', International Sociology 13(1): 95-115.

Locke, R.M. and M. Romis (2007) 'Improving Work Conditions in Global Supply Chains', MIT-Sloan Management Review 48(2): 54-62.

Locke, R.M., M. Amanguel and A. Mangla (2009) 'Virtue Out of Necessity: Compliance, Commitment, and the Improvement of Labor Standards', Politics \& Society 37(3): 319-51.

Locke R.M., F. Qin, L. Brause et al. (2007) 'Does Monitoring Improve Labor Standards? Lessons from Nike', Industrial and Labor Relations Review 61(1): 3-31.

Lund-Thomsen, P. (forthcoming) 'Labor Agency in the Football Manufacturing Industry of Sialkot, Pakistan', Geoforum.

Lund-Thomsen, P. and K. Nadvi (2009) 'Global Value Chains, Local Clusters, and Corporate Social Responsibility: A Comparative Assessment of the Sports Goods Clusters in Sialkot, Pakistan and Jalandhar, India'. Technical Paper 17, Industrial Policy and Private Sector Development Branch. Vienna: United Nations Industrial Development Organization.

Lund-Thomsen, P. and K. Nadvi (2010) 'Clusters, Chains and Compliance: Corporate Social Responsibility and Governance in Football Manufacturing in South Asia', Journal of Business Ethics 93(2): 201-22.

Milberg, W. and D. Winkler (2011) 'Economic and Social Upgrading in Global Production Networks: Problems of Theory and Measurement', International Labour Review 150(3-4): 341-65.

Miller, D., S. Turner and T. Grinter (2010) 'Back to the Future? Mature Systems of Industrial Relations Approaches and Social Upgrading in Outsourced Apparel Supply Chains'. Working Paper 2010/02. Manchester: University of Manchester.

Nadvi, K. (2008) 'Global Standards, Global Governance and the Organisation of Global Value Chains', Journal of Economic Geography 8(3): 323-43.

Nadvi, K. (2011) 'Labour Standards and Technological Upgrading: Competitive Challenges in the Global Football Industry', International Journal of Technological Learning, Innovation and Development 4(1-3): 235-57.

Nadvi, K. and F. Wältring (2004) 'Making Sense of Global Standards', in H. Schmitz (ed.) Local Enterprises in the Global Economy, pp. 53-94. Cheltenham: Edward Elgar.

Nadvi, K. with P. Lund-Thomsen and H. Xue (2011) 'Playing against China: Global Value Chains and Labour Standards in the International Sports Goods Industry', Global Networks 11(3): 334-54. 
Neilson, J. and B. Pritchard (2009) Value Chain Struggles: Institutions and Governance in the Plantations of South India. Gloucester: Wiley-Blackwell.

Neilson, J. and B. Pritchard (2010) 'Fairness and Ethicality in their Place: The Regional Dynamics of Fair Trade and Ethical Sourcing Agendas in the Plantation Districts of South India', Environment and Planning A 42: 1833-51.

Nelson, V., A. Martin and J. Ewert (2007) 'The Impacts of Codes of Practice on Worker Livelihoods', Journal of Corporate Citizenship 28: 61-78.

Oxfam (2010) 'Better Jobs in Better Supply Chains'. Briefings for Business No. 5. Oxford: Oxfam International.

Ponte, S. and P. Gibbon (2005) 'Quality Standards Conventions, and the Governance of Global Value Chains', Economy and Society 34(1): 1-31.

Pun, N. (2005) 'Global Production and Corporate Business Ethics: Company Codes of Conduct Implementation and its Implication on Labour Rights in China', China Journal July: 101-13.

Rainnie, A., A. Herod and S. McGrath-Champ (2011) 'Review and Positions: Global Production Networks and Labour', Competition and Change 15(2): 155-69.

Riisgaard, L. and N. Hammer (2011) 'Prospects for Labour in Global Value Chains: Labour Standards in the Cut Flower and Banana Industries', British Journal of Industrial Relations 49(1): 168-90.

Schmitz, H. (ed.) (2004) Local Enterprises in the Global Economy: Issues of Governance and Upgrading. Cheltenham: Edward Elgar.

Selwyn, B. (2012) 'Beyond Firm Centrism: Re-integrating Labour and Capitalism into Global Commodity Chain Analysis', Journal of Economic Geography 12(1): 247-71.

Sum, N.L. and N. Pun (2005) 'Paradoxes of Ethical Transnational Production: Codes of Conduct in a Chinese Workplace', Competition and Change 9(2): 181-200.

UN Comtrade (2011) 'United Nations Commodity Trade Statistics Database'. New York: United Nations, Statistic Division.

Usher, A. and K. Newitt (2009) 'Beyond Auditing: Tapping the Full Potential of Labour Standards Promotion'. Utrecht: IDH Dutch Sustainable Trade Initiative.

Xue, H. (2011) 'Outsourcing in China: Wal-Mart and Chinese Manufacturers', in A. Chan (ed.) Walmart in China, pp. 34-53. Ithaca, NY: Cornell University Press.

Peter Lund-Thomsen is associated with the Center for Corporate Social Responsibility and Center for Business and Development Studies, and associate professor in the Department of Intercultural Communication and Management, Copenhagen Business School, Porcelaenshaven 18A, 2000 Frederiksberg, Denmark (e-mail: plt.ikl@cbs.dk). His research interests focus on corporate social responsibility in developing countries, global value chains, and industrial clusters. His work has appeared in journals such as Competition and Change, Geoforum and the Journal of Business Ethics.

Khalid Nadvi is senior lecturer at the School of Environment and Development, University of Manchester, Arthur Lewis Building, Oxford Road, Manchester M13 9PL, UK (e-mail: khalid.nadvi@manchester.ac.uk). His widely published research on globalization focuses on the interface between local clusters and global production, global regulation and local outcomes. He leads an ESRC funded research network on Rising Powers and Global Standards and his current research project is on the rising powers, labour standards and the governance of global production networks. 
Anita Chan is a research professor at the China Research Centre, University of Technology Sydney, PO Box 123, NSW 2007, Sydney, Australia (e-mail: anita.chan@uts.edu.au). She has published widely on Chinese labour issues, rural China, Chinese youth and comparative labour. She is the editor of Walmart in China (Cornell University Press, 2011) and Labour in Vietnam (ISEAS Publishing, 2011). Her current research focuses on the industrial relations of China's automobile industry and comparative labour standards for China and Vietnam's foreign-invested industries.

Navjote Khara is a professor at the Centre for Business, George Brown College, 200 King Street East, Toronto, ON, M5A 3W8, Canada (e-mail: nkhara@georgebrown.ca). Her research interests focus on global value chains, industrial clusters and corporate social responsibility in the developing countries. She has worked on projects with UNIDO, the Copenhagen Business School and the Institute of Industrial Policy Studies, South Korea. Her work has been published in Global Networks, European Journal of International Management and Indian Journal of Marketing.

Hong Xue is a lecturer at the Department of Sociology, School of Social Development, East China Normal University, 500 Dongchuan Road, Minhang, Shanghai, 200241, China (e-mail: xuehong005@gmail.com). Her research interests include labour, civil society and global production networks. Her research has been published in International Labour and Working Class History, Global Networks and several academic journals in Chinese. Her chapter on the relationship between Chinese suppliers and their global buyers appeared in Wal-Mart in China edited by Anita Chan (Cornell University Press, 2011). 